\title{
Transición de jóvenes varones en conflicto con la ley penal hacia la vida adulta en Córdoba (Argentina)
}

\author{
Transition of young males in conflict with the \\ criminal law towards adult life in Córdoba
} (Argentina)

\section{Transição de jovens rapazes em conflito com a lei penal à vida adulta em Córdoba (Argentina)}

ORCID ID: 0000-0002-1227-3255

Universidad Católica de Córdoba-Unidad Asociada al CONICET / Unidad Ejecutora UCC-CONICET, Argentina

Patricia Dubini

ORCID ID: 0000-0002-1339-7276

Universidad Católica de Córdoba-Unidad Asociada al CONICET / Unidad Ejecutora

UCC-CONICET, Argentina

Ana S. Gonzalez ORCID ID: 0000-0002-3634-3609 Universidad Católica de Córdoba-Unidad Asociada al CONICET / Unidad Ejecutora UCC-CONICET, Argentina

Autor referente: griseldacardozo656@hotmail.com

Historia editorial

Recibido: 25/11/2018

Aceptado: 08/04/2019

\section{RESUMEN}

El objetivo del trabajo es analizar los modos en que se produce la transición hacia la adultez en jóvenes varones en conflicto con la ley penal privados de libertad. Se exploran los cambios y

continuidades en sus trayectorias vitales (familiares, laborales, educativas), se indagan aspectos relativos a eventos significativos considerando sus interrelaciones $y$ 
confluencias para comprender cómo intentan armar proyectos, buscar respuestas a los obstáculos que enfrentan, movilizar recursos y tomar decisiones de cara al futuro. Se optó por un abordaje cualitativo y se utilizó como herramienta metodológica el relato biográfico. A partir de entrevistas en profundidad se fueron elaborando los relatos de cinco jóvenes de entre 18 y 19 años de edad alojados en un centro socioeducativo penal juvenil de privación de la libertad (Córdoba, Argentina). A partir del software Atlas $\mathrm{Ti}$ se codificaron y analizaron los datos de manera simultánea, identificándose cuatro categorías centrales en la construcción de las trayectorias que marcan el camino de transición hacia la adultez: a) la urdimbre familiar, b) la experiencia escolar, c) la experiencia laboral, d) el papel del encierro en la transición a la adultez. Los jóvenes señalan una sucesión de eventos significativos que fueron trazando sus itinerarios biográficos que se combinan en el presente con el encierro, en el marco de un sistema punitivo y de control, y con un seguir "atrapados" ante un futuro que se vislumbra como incierto.

Palabras clave: Transición a la vida adulta; jóvenes en privación de libertad; trayectorias de vida; desigualdad social

\section{ABSTRACT}

The aim of this work is to analyze the ways in which the transition to adulthood occurs in incarcerated young men who have been in conflict with criminal law. The research explores their life trajectories (family, work, education), capturing major divergences, the inter connections of significant life events are investigated with regard to how the young men approach their major decisions, find answers to the obstacles they face, mobilize resources and make decisions about their future. A qualitative approach was chosen using biographical narrative methodology. Based on in-depth interviews, the stories of five young people between 18 and 19 years of age housed in a socio-educational juvenile justice detention center (Córdoba, Argentina) were gathered. The data were coded and analyzed simultaneously using Atlas $\mathrm{TI}$ software, and four central categories were identified, describing trajectories that mark the path of transition towards: a) family history, b) school experience, c) work experience, and d) the role of confinement in the transition to adulthood. Young people point out a succession of significant events in their biographical itineraries, combining the present experience with confinement, the framework of the punitive and control system, and with feeling "trapped" in the face of an uncertain future.

Key words: Transition to adult life; young people in deprivation of liberty; life trajectories; social inequality

\section{RESUMO}

O objetivo do trabalho é analisar as formas em que se produz a transição à idade adulta em jovens rapazes em conflito com a lei penal privados de liberdade. Exploram-se as mudanças e a continuidade nas suas trajetórias 
vitais (familiares, trabalho e educativas). Indagam-se aspectos relativos a eventos significativos considerando suas inter-relações e confluências para compreender como tentam preparar projetos, encontrar respostas aos obstáculos que enfrentam, mobilizar recursos e tomar decisões frente ao futuro. Optou-se por uma abordagem qualitativa e utilizou-se como ferramenta metodológica 0 relato biográfico. A partir de entrevistas mais profundas foi-se elaborando os relatos dos cinco jovens de 18 e 19 anos alojados num centro prisional juvenil socioeducativo privados de liberdade (Córdoba, Argentina). A partir do software Atlas $\mathrm{Ti}$ codificarem-se e analisaram os dados simultaneamente, identificando-se quatro categorias centrais na construção das trajetórias que marcam o caminho de transição à vida adulta: a) o entorno familiar, b) a experiência escolar, c) a experiência trabalhista, d) o papel do isolamento na transição a idade adulta. Os jovens demonstram uma sucessão de eventos de vida significativos que foram traçando seus itinerários biográficos que combinam entre o presente com 0 isolamento, no quadro de um sistema punitivo e controlador, e com um seguir "preso" diante de um futuro que se vislumbra como incerto.

Palavras chave: Transição à vida adulta; jovens em privação de liberdade; trajetórias de vida; desigualdade social

a juventud es la etapa en la que las personas se preparan para asumir las responsabilidades de la vida adulta, cuando se definen proyectos vitales y se establecen prioridades y objetivos de futuro. Este pasaje implica un proceso de cambio, de individualización, de resolución de conflictos, de asunción de nuevos roles y de toma de decisiones en pro de lograr una vida autónoma y responsable (Krauskopf, 2015).

En Latinoamérica, los estudios sobre juventud (Mora Salas \& de Oliveira, 2014), y más precisamente en nuestro país (Miranda \& Corica, 2018), demuestran que las transformaciones socioculturales y económicas de finales de siglo, incidieron fuertemente en la construcción de las trayectorias juveniles y por ende en los procesos de transición hacia la vida adulta, en función de la diversidad de experiencias, roles y sentidos que adquieren las mismas (Roberti, 2017).De hecho, las rutas que tomaban los jóvenes entre la escuela y el trabajo en la actualidad se ven sustituidas por movimientos más fragmentados que acontecen en terrenos laberínticos, por lo que las transiciones de los jóvenes pasaron de ser lineales a ser más prolongadas, complejas y 
desestandarizadas (Miranda \& Corica, 2018). Es difícil predecir la trayectoria de un joven hacia la vida adulta, hay múltiples posibilidades: cada uno construye su ruta y su calendario, sin perder de vista los condicionamientos estructurales.

Las investigaciones realizadas en Argentina (Di Leo \& Camarotti, 2017) y en Córdoba en particular (Ministerio de Trabajo, Empleo y Seguridad Social. Presidencia de la Nación, 2018) reflejan que comprender el tránsito a la vida adulta como proceso diferenciado implica reconocer que los colectivos juveniles pertenecientes a sectores populares presentan otras complejidades que se derivan de la distribución desigual de bienes en la población y de las escasas oportunidades de inclusión social que se les brinda.

Para estos jóvenes, y más específicamente para los jóvenes varones, los itinerarios biográficos se encuentran atravesados por múltiples problemáticas: la pobreza, la exclusión del sistema educativo, el ingreso temprano al sistema laboral informal, la violencia sufrida en distintos ámbitos, la incorporación a redes de narcotráfico y los conflictos familiares que muchas veces derivan en el abandono temprano del hogar. Se conjugan así dos condiciones: de clase y de género. Son así, generalmente los varones provenientes de sectores populares los que tienen mayor riesgo de quedar atrapados por el sistema penal (Crisafulli \& León Barreto, 2015).

En este marco, la situación se complejiza para los jóvenes que se encuentran en contextos de encierro. Su tránsito hacia la vida adulta está marcado por una libertad en continua fragilidad, con la posibilidad de reincidir y con escasez de oportunidades. Vuelven a recurrir a soportes ilegales (robo, venta de drogas) para poder subsistir (Gonzales \& Trillo, 2015).De este modo se pone en juego un limitado acceso a espacios de realización personal, por lo que en estos casos de privación extrema la posibilidad de proyectarse se ve truncada. El futuro se ve como incierto, lejano e imprevisible en tanto el presente está subordinado a la subsistencia (Mora Salas \& de Oliveira, 2014). Si bien la evidencia empírica arroja estudios en Latinoamérica que abordan la transición de los jóvenes en situación de encierro hacia la adultez, en nuestro contexto no se 
consideran suficientes los datos recabados por lo que las soluciones suelen no adecuarse a las necesidades de reinserción social. Conocer sus trayectorias debiera ser una prioridad a los fines de generar propuestas tendientes a delinear un futuro que permita dar una respuesta diferente a las problemáticas que presentan (González-Laurino, 2015), así como problematizar la noción normativizante de proyecto de vida.

Ante este panorama, este estudio presenta reflexiones y avances preliminares de un proceso de investigación en curso. Se propone explorar los modos en los que se produce la transición hacia la adultez y particularmente las trayectorias de vida de los jóvenes en conflicto con la ley penal. Para tal fin, se indagan los cambios y continuidades en las trayectorias vitales (familiares, laborales, educativas) así como los aspectos relativos a eventos significativos. Se consideran sus interrelaciones y confluencias para conocer cómo intentan los jóvenes armar proyectos, buscar respuestas a los obstáculos que enfrentan, movilizar recursos y tomar decisiones de cara al futuro. Atendiendo a estos objetivos se formularon los interrogantes que guiaron el trabajo: ¿Qué características presenta la transición hacia la adultezen jóvenes varones en conflicto con la ley penal privados de libertad? ¿Cuáles son las posibilidades y/o dificultades que enfrentan al transitar sus trayectorias familiares, educativas y laborales? ¿Qué marcas deja el encierro en sus proyecciones a futuro?

Para responder estas preguntas, se sigue la sugerencia de estudios en los que se plantea la necesidad de nuevos abordajes metodológicos que tengan en cuenta la diversidad de formas que presentan las trayectorias y transiciones juveniles. En este punto la perspectiva biográfica (Lecler-Olive, 2009) se considera un marco referencial pertinente al tomar a la juventud como sujeto histórico, protagonista de su propia vida a partir de elecciones y decisiones que asume bajo determinaciones socio-culturales (Roberti, 2017). 


\section{Caracterización del sistema de responsabilidad penal juvenil en Argentina}

La década de 1990 y los primeros años del siglo XXI han resultado un progreso en cuanto al reconocimiento de los derechos de niños, niñas y adolescentes. En esta línea se deroga la Ley Nacional del Patronato de Menores 10.903 (1919), se incorpora la Convención Internacional del Niño a la Constitución Argentina y se sanciona la Ley Nacional de Protección Integral de los Derechos de Niñas, Niños y Adolescentes 26.061 (2005). Estas intervenciones del Estado vienen a poner fin, en teoría, a la criminalización de los problemas sociales tanto en la infancia como en la juventud y con ello la intención orientada a prevenir la vulnerabilidad de este grupo etario. No obstante, los delitos efectuados por menores de edad en la Argentina se siguen abordando con el decreto Ley $\mathrm{N}^{\circ} 22.278$ (1980) que tiene su origen en la dictadura y que autoriza a los jueces a definir el destino de esos jóvenes. El fundamento y la aplicación de esta norma entra en contradicción con la mencionada Ley 26.061 (2005), en particular al mantener la disposición tutelar de la Ley 10.903 del Patronato de la infancia (1919) (Salazar, 2018). De este modo, tal como publica el Ministerio de justicia y derechos humanos de la Nación (2019) existen un poco más de 100 menores de 16 años -considerados inimputables por la ley- privados de su libertad por la decisión discrecional de algún magistrado, sin control y sin responder a un proceso judicial ni a una condena.

Igualmente, el relevamiento de la Secretaría Nacional de Niñez, Adolescencia y Familia (SENNAF) junto a UNICEF (2015) señala que en la Argentina las prácticas institucionales destinadas al tratamiento de las niñas, niños y adolescentes en conflicto con la ley penal son heterogéneas y con resultados variados. En este sentido, se reconoce que la frecuencia de adopción de penas privativas de la libertad todavía es alta y no se la aplica como recurso excepcional y por el menor tiempo posible. Los datos del relevamiento indican que el $51,7 \%$ de los dispositivos penales juveniles existentes en el país son establecimientos de privación de libertad, de los cuales el 70,5\% son centros 
de régimen cerrado, donde se alojan en su mayoría varones y dependen de áreas especializadas en Niñas, Niños y Adolescentes; le siguen aquellos dispositivos de restricción de libertad (26,3\%) y, finalmente, los dispositivos de supervisión en territorio (22\%). Asimismo, este estudio registró 3.908 adolescentes infractores o presuntamente infractores hasta 17 años de edad (incluyendo los no punibles) y 2.960 de 18 años o más. El total de jóvenes presentes en los dispositivos fue de 7.178 (en 310 casos no se pudo establecer con precisión la edad). De éstos, 5.701, es decir, casi el $80 \%$, se encontraba en programas de Supervisión de Territorio. Los jóvenes comprendidos en dispositivos de restricción o privación de libertad eran 1.477 (1.305 en establecimientos cerrados de privación de libertad y 172 en residencias educativas).

El informe sostiene que, en estos últimos diez años, se ha buscado ampliar la accesibilidad de derechos en materia penal juvenil. Teniendo como marco la Ley $\mathrm{N}^{\circ}$ 26.061 (2005) la SENNAF ha trazado los lineamientos para el diseño y la implementación de un sistema penal juvenil acorde a los Derechos Humanos sustentado en base a principios de "especialización, excepcionalidad, accesibilidad de Derechos y la promoción de medidas tendientes al cumplimiento de la sanción en territorio" (SENNAF \& UNICEF, 2015, p. 43). En esta misma línea, el informe afirma que hacia el interior de los dispositivos penales han buscado asegurar que la privación de libertad no vulnere otros derechos. Se incrementaron las actividades educativas, recreativas y de formación en los centros de régimen cerrado, lo cual refleja un avance de la educación formal junto con las intervenciones no formales al interior de estas instituciones.

Cabe aquí el interrogante por la efectividad de estas prácticas e intervenciones en materia penal juvenil a partir de los datos que arroja el informe. En este contexto, desde el Ministerio de Justicia y Derechos Humanos de la Nación (2019) se sostiene la necesidad de contar con un sistema penal juvenil especializado, que esté en concordancia con los estándares internacionales de derechos humanos. Para tal fin se 
crea en el año 2017 la "Comisión de Trabajo para un Nuevo Sistema de Responsabilidad Penal Juvenil" con el objetivo de debatir y elaborar los lineamientos esenciales para un nuevo sistema de responsabilidad penal juvenil. Fruto del trabajo de la Comisión se presenta un anteproyecto de ley, que tiene en cuenta cuatro ejes fundamentales:

1) contar con una justicia especializada, 2) abordar los problemas desde una perspectiva multidisciplinaria y restaurativa, 3) fomentar en el niño o el adolescente el sentido de la responsabilidad por sus actos, 4) procurar la integración social de los jóvenes e involucrar activamente a las víctimas. (Ministerio de justicia y derechos humanos de la Nación, 2019)

Finalmente, Salazar (2018) sostiene que no sólo es necesario realizar las adecuaciones a los estándares de derecho, sino también es fundamental que los sistemas de protección lleguen tempranamente y de modo eficaz a las comunidades vulneradas para evitar el ingreso de los y las jóvenes al circuito penal.

\section{Método de estudio}

El proceso de investigación se realizó desde un enfoque cualitativo y adoptó un diseño de tipo exploratorio. Intenta recortar un fenómeno microsocial en función de comprender e interpretar las significaciones y aspectos afectivos vinculados a las historias de vida de los jóvenes entrevistados. Empleamos el relato biográfico (Leclerc-Olive, 2009) como herramienta, ya que permite un despliegue narrativo de las experiencias vitales del sujeto a lo largo del tiempo, por lo que la dimensión temporal -en el anudamiento entre las experiencias vividas (pasado), las vivencias en curso (presente) y las experiencias previsibles (futuro probable)- cobra una importancia particular. 


\section{Procedimiento}

La construcción de los relatos se logró a través de cinco entrevistas en profundidad realizadas a cada uno de los jóvenes, a partir de las cuales, se obtuvo una narración que permitió dar cuenta del testimonio subjetivo de los acontecimientos y de las valoraciones que cada joven hace de su propia vida. Los encuentros duraron aproximadamente dos horas cada uno y se llevaron a cabo en horarios y espacios asignados en uno de los pabellones de la institución en la que se encontraban alojados previamente acordados buscando cuidar la mayor confidencialidad y bienestar. Cada una de las entrevistas fueron desgrabadas y transcriptas a los fines de ser trabajadas en cada encuentro con los jóvenes. Finalmente, se les propuso representar gráficamente su historia, señalando los momentos críticos experimentados y que condujeron a modificar el curso de sus vidas. En base a esta producción y, respetando la textualidad de los enunciados, se fue dando forma al relato final.

Para la realización del trabajo se tomaron los recaudos éticos. En primer lugar, se solicitó la autorización a la institución para llevar a cabo el estudio y, en una segunda instancia, se procedió a la firma del consentimiento informado a partir del cual los jóvenes pudieron tomar conocimiento de los objetivos del trabajo y del uso que se daría a los datos que ofrecían. Se les informó acerca del compromiso de entregarles al final del proceso el relato construido. Asimismo, se les manifestó que no interesaban sus actividades delictivas, sino sus trayectorias de vida, las situaciones vividas y los contextos en que éstas se desarrollaban. En todo momento la experiencia se enmarcó en un vínculo de confianza para reducir al mínimo cualquier sentido de obligatoriedad y vulneración de derechos. Finalmente, se modificó toda información que permitiera identificarlos.

\section{Participantes}

El estudio se realizó en un centro socioeducativo cerrado de la ciudad de Córdoba que 
recibe a jóvenes en conflicto con la ley penal - con sentencia firme o no - y que acorde a la normativa vigente debieran tener entre 16 y 18 años, aunque en la realidad se encuentran alojados jóvenes por debajo o encima de esta edad. Trabajamos con cinco jóvenes de entre 18 y 19 años de edad que se encontraban en uno de los pabellones durante el período en que duró la recolección de datos (julio - septiembre de 2017). La selección de los mismos se realizó a partir de un muestreo intencional que contempló como principales criterios de inclusión la edad (ser mayor de 17 años) y la participación voluntaria en el estudio. En la tabla 1 se presenta información sobre los datos sociodemográficos.

Tabla 1

Características Sociodemográficas de los Jóvenes Entrevistados

\begin{tabular}{llllll}
\hline & & & Trabajo & Tiempo en la & Estado civil/ \\
Nombre & Edad & Trabajo padre & madre & institución & Hijo \\
\hline Lautaro & 19 & Albañil & Trabaja & Año y medio & Soltero \\
& & & geriátrico & & \\
Marcos & 18 & Docente & Ama de casa & Año y medio & En pareja, \\
& & secundario & & & un hijo \\
Kevin & 19 & Empleado & Ama de casa & Año y medio & En pareja \\
& & fábrica & & & Soltero \\
Mariano & 18 & No trabaja/Preso & Ama de casa & Año y medio & Soltero \\
Gerardo & 19 & Camionero & Portera & Dos semanas & \\
\hline
\end{tabular}

\section{Análisis de datos}

Para la construcción y análisis de datos se empleó la estrategia de la comparación constante (Glaser \& Strauss, 1967) a partir de la cual se recogieron, codificaron y 
analizaron los datos de manera simultánea utilizando como auxiliar el software Atlas. Ti versión 7.5.4. En la construcción de las trayectorias que marcan el camino de transición hacia la adultez de los jóvenes, se identificaron cuatro categorías emergentes desde las entrevistas y relatos construidos: a) la urdimbre familiar, b) la experiencia escolar, c) la experiencia laboral y, d) el papel del encierro en la transición a la adultez. Con el fin de no sobrepasar la extensión máxima del artículo se presentan en torno a cada categoría central, fragmentos de relatos a modo de ilustración.

\section{Resultados}

\section{La urdimbre familiar y las desventajas sociales heredadas}

Se ha comprobado el impacto que cobra en las trayectorias vitales de los jóvenes la acumulación persistente de desventajas sociales y, en particular, las condiciones relacionadas al origen familiar (Tenenbaum, 2016). En este marco, la narrativa de los jóvenes giró en torno a dos ejes que se entrelazan entre sí: por un lado, las condiciones estructurales y, por otro, la característicasy dinámica familiar.

Los relatos abundan sobre este primer eje: carencias que afectan a las familias de los jóvenes y que ellos reconocen como "sus" orígenes. Han sido marcados por múltiples privaciones que derivan en la transmisión de las desigualdades sociales asociadas a la pobreza (condiciones laborales, de educación y lugar de residencia) y que se reproducen de generación en generación. Si bien en todos los relatos puede constatarse este panorama poco esperanzador, uno de los jóvenes lo acentúa como determinante:

Vivo en el barrio BF. Es un barrio bajo, hay gente pobre, gente humilde a la que nadie ayuda. Todos los días hay problemas con la policía, en la esquina se juntan los chicos, los corren, ellos se van y empiezan a tirarse tiros con la policía, porque están drogados, roban en el mismo barrio. (Kevin, relato de vida, 2017) 
Desde el segundo eje, y en relación a las características y dinámica familiar, se desprende una gama de experiencias que dan cuenta de una urdimbre que se teje en torno a sus historias delimitada por la composición familiar, la condición de ser hijos varones y los modos de convivencia.

Se evidencia que si bien esta red no conforma una trama permanente/continua en el tiempo que contrarreste las carencias del pasado les brindó sostén ante situaciones de desamparo. Recuperan la figura de sus tíos como protectoras cuando se alejan del hogar: "Mi tío trabajaba de albañil y me daba plata. Mi tía trabajaba en el negocio de su hermano, yo estaba ahí y a veces llevaba los chicos a la escuela" (Lautaro, relato de vida, 2017).

Para otros, la familia cobra relevancia tanto en el pasado como en el presente con respecto a la vida en la institución:

Mi viejo y mi tía vienen más, siempre fui muy apegado a ella. Me ayudaba cuando yo no tenía plata o cuando estaba mal, yo le contaba cuando me 'peliaba' con mi novia o cuando tenía problemas con mi hijo, cuando le pegaba iba y le contaba y ella me aconsejaba. (Marcos, relato de vida, 2017)

Otras situaciones se asocian a la presencia o ausencia del padre/madre y la posición de los jóvenes entre los hermanos/as. Condiciones que, en su conjunto, se enlazan a modo de un tejido conspirativo complejizando la posibilidad de organizar un proyecto a futuro. Los relatos dan cuenta de las dificultades que se presentan a partir de la composición familiar y la conflictividad en torno a los modos de vincularse entre padres e hijos y en la fratría:

Somos diez hermanos. Mi hermano más grande tiene 25 y el menor 4 , uno fue dado en adopción y una de mis hermanas formó pareja y se fue a vivir a otra provincia. Todos los días peleábamos con mi hermano mayor porque él trabaja de albañil, llegaba los viernes y mi papá no le pedía plata para que ayude en la casa, pero él tampoco se daba cuenta que a mi papá y a mi mamá les hacía falta. 
Se gastaba toda la plata en drogas, salía un viernes y volvía el domingo. Llegaba y quería que mi mamá le diera la comida,[...] o le faltaba el respeto y mi mamá siempre lloraba. Yo la veía a mi mamá, y le decía que no le falte el respeto y terminábamos discutiendo y a las piñas. (Kevin, relato de vida, 2017)

Así, violencia familiar, consumo de sustancias, y dificultades económicas se convierten en factores que refuerzan la fragilidad de los lazos familiares. En casos extremos se suma a estas condiciones, la historia de delito de sus familiares como narra uno de los jóvenes entrevistados:

Mi papá estuvo preso por robo, trabajaba de albañil. Era violento con nosotros, tomaba, se drogaba. Nunca me ayudó para pensar que yo tenía que elegir otro camino. A mi papá hace mucho que no lo veo, no me quiere visitar. (Lautaro, relato de vida, 2017)

En este caso, encontramos una historia signada por una sucesión de abandonos (la separación de la pareja parental, la vida en el orfanato junto a sus hermanos a sus seis años, el suicidio de su tío materno con quien vivió luego de salir del orfanato, el posterior abandono del hogar de su padre y hermanos mayores) que delimitan una experiencia autobiográfica marcada por identificaciones lábiles a adultos que, por la precariedad de sus vidas y angustias desbordantes, poco pueden donar y albergar. Experiencias vitales que tal como puede narrar lo condujeron a "no poder elegir otro camino que no fuera la vida en la calle" (Lautaro, relato de vida, 2017).

En suma, los relatos de estos jóvenes demuestran que, en los casos más extremos, la familia pasa a convertirse en el escenario donde los mismos sufren situaciones de riesgo que los exponen a conductas y hasta alientan su participación en actividades asociadas con la drogadicción y el robo. Desde estas experiencias se advierte una articulación entre el papel del sistema familiar y la aparición de conductas delictivas en los hijos (Bobbio, Lorenzino, \& Arbach, 2016). De este modo y ante situaciones extremas "la familia se constituye en un factor que contribuye a desestructurar las 
trayectorias de vida de los jóvenes y se articula con otras fuerzas que favorecen las dinámicas de exclusión social” (Mora Salas \& de Oliveira, 2014, p. 89), que facilitan o restringen la matriz de oportunidades disponibles en la construcción de trayectorias por rutas diferentes a los orígenes.

\section{El tránsito por la institución escolar}

El nivel educativo de los padres resulta una variable fundamental en la constitución de la trama simbólica y capital cultural de los hijos y determina la manera en que éstos se vinculan con el conocimiento y la escuela. Así, el profundo distanciamiento entre las familias y el sistema educativo formal juega un papel relevante en la no permanencia de los jóvenes en este ámbito (Sandoval Obando, 2014). Esta situación se constata en las historias de los jóvenes, cuyos padres son analfabetos o con una limitada escolaridad, a excepción de Marcos cuyo padre tiene estudios superiores.

Asimismo, sus trayectorias escolares muestran un carácter errático. En consonancia con los trabajos de Roberti (2017) la etapa de escolarización formal es breve y está signada por ciclos discontinuos que trazan un camino marcado por la repitencia y el abandono escolar, por lo que fue posible identificar diferentes posicionamientos al respecto: Para algunos jóvenes el tránsito por la escuela primariare presenta un escenario de dificultades académicas y de manifestaciones disruptivas: "Fui a la escuela, tenía mala nota, mal comportamiento, peleaba con los chicos, puteaba a las maestras, me iba de clase" (Lautaro, relato de vida, 2017).

Para otros, la escuela dejó en ellos una marca de identidad de carácter estigmatizante:

De chico no me acuerdo de nada porque tengo discapacidad, me dieron en el lo quero [el diagnóstico]. Me llevaron ahí porque las maestras me dijeron que no sé leer o escribir, ahí me iban a revisar. De mi familia, todos saben escribir, menos mi papá. De mis hermanos, todos menos yo. Hasta mi hermanita de ocho años sabe leer. (Mariano, relato de vida, 2017) 
En ocasiones la escuela primaria transcurría entre logros y fracasos:

Y estuve ahí entre notas buenas, notas malas. Por ahí me querían hacer repetir de vuelta [había repetido segundo grado], iba mi mamá se quejaba y hasta el último supe ser abanderado [evoca con cariño a las maestras que lo ayudaron]. Todas las maestras eran buenas. Me acuerdo la de música en todo el primario, con la que más me llevaba, me traía canciones de cuarteto que le pedía, hasta zapatillas. (Gerardo, relato de vida, 2017)

En contraposición, para otros jóvenes concurrir a la escuela tenía sentido: "Siempre me gustó. Nunca me llevé materias. Siempre me fue bien, siempre fui de prestar atención. Me gusta biología, las otras materias no me gustan tanto. Una sola vez falté nomás, que me hice la chupina como le dicen" (Marcos, relato de vida, 2017).

En relación al paso por la escuela secundaria, la mayoría deserta después de repetir el primer año y mencionan como causa factores externos a la institución. En algunos casos aluden a las dificultades académicas y a la sobreedad:

Yo repetí en el primario segundo grado y después primer año. Como le dije a mi vieja: Yo a la escuela la voy a dejar porque cada vez me está yendo más mal. Me llevaba casi como dos años con los chicos, era grande y no me gustaba ir con chicos muy chicos (Gerardo, relato de vida, 2017).

Para otros las razones son económicas: "Dejé la escuela secundaria porque no me gustaba, le dije a mi mamá que quería mi plata" (Lautaro, relato de vida, 2017). Igualmente, se hace evidente el desencuentro entre los intereses, códigos y formas de sociabilidad propias de los contextos grupales barriales y aquellos que circulan en la escuela: "Me empecé a juntar con chicos más grandes que ya andaban fumando cigarrillos y tomando drogas y dejé la escuela" (Kevin, relato de vida, 2017).

En relación a la posibilidad de continuar con los estudios, son diversas las expectativas que enuncian. Para algunos la opción se presenta como un deseo a futuro apostando a seguir el modelo familiar: "Algún día, si Dios quiere, me voy a recibir de profesor de 
biología [como mi papá], pero tenés que saber cómo se hacen las cosas, tenés que estudiar" (Marcos, relato de vida, 2017); para otros la oportunidad emerge luego de poder pensar en la condición de libertad: "Quiero terminar el secundario, ya estoy anotado, me iban a recibir, pero primero tengo que salir de acá" (Kevin, relato de vida, 2017); finalmente la opción surge ante la expectativa de conseguir trabajos estables y mejor remunerados, tal como lo expresa uno de los jóvenes:

Hoy si no sabes leer, si no sabes escribir no te toman en ningún lado. Y por eso se me vino a la cabeza que quiero empezar de vuelta la escuela, para ver si puedo empezar en un trabajo fijo (Gerardo, relato de vida, 2017).

En resumen, se advierte que el paso por la institución aparece atravesado por el fracaso escolar, pero en general el mismo no es experimentado de un modo conflictivo, incluso la deserción no es registrada como un evento especialmente relevante (Kessler, 2006). Los jóvenes tienden a dar explicaciones que no cuestionan la lógica institucional, sino que se responsabilizan de su propio fracaso.

La escuela se presenta de este modo como un ideal que no logra resolver la tensión entre la urgencia y el proyecto que despliegan en esta etapa de sus vidas, atrapada en una lógica contradictoria: entre la estrategia de reproducción de lo heredado a corto plazo y la estrategia de formación a largo plazo (Roberti, 2017).

\section{La experiencia laboral: ganar para subsistir / ganar para la droga}

La inserción en el trabajo se configura a partir de dimensiones estructurales y biográficas, lo que implica la actualización de diferentes recursos (heredados y adquiridos), así como las representaciones sociales, las proyecciones personales y las propias decisiones frente a las oportunidades o a las limitaciones del contexto. La inestabilidad, la precariedad, la baja remuneración y la carencia de cobertura social no son para muchos jóvenes problemas nuevos, en muchos casos ya han sido experimentados por sus padres (subempleados o desempleados) quienes les 
transmiten la resignación a unas reglas de juego que los excluye de todos los derechos sociales (Milillo, Torillo \& Farías, 2016). Podría decirse que, en general, éste es el escenario en el que va surgiendo la temática laboral para estos jóvenes.

En sus narrativas expresan los motivos por los cuales ingresaron tempranamente a la vida laboral. Para algunos surge con fuerza la idea de trabajar para ayudar como una estrategia familiar de subsistencia: "Mi papá cuando trabajaba ayudaba a mi vieja con plata, pero después no la ayudó más cuando se "pelió" y se fue, yo cuando trabajaba ayudaba a mi mamá a pagar las cuentas" (Lautaro, relato de vida, 2017).

Otro de los jóvenes expresa que esta necesidad se constituye en una cuestión ligada a un "deber ser", a una cuestión moral:

Yo veía media corta a mi familia de plata. Siempre estuve apoyando a mi familia. Yo ponele trabajaba de lunes a viernes, sacaba 2.000 pesos y le daba $1.500 \mathrm{a} \mathrm{mi}$ familia y yo me quedaba con 500 , porque si yo me ponía a pensar, ellos me criaron, me dieron de comer, me están aguantando hasta ahora (Gerardo, relato de vida, 2017).

Diferente es la situación de aquellos para quien la utilización del dinero sirve para satisfacer sus necesidades, sin importar su procedencia, por lo que delito y trabajo no aparecen como excluyentes:

Hablamos con mi papá y le dije que me iba a hacer cargo [del hijo] que no le iba a faltar nada. Porque yo le dije a la madre cuando tenía 16 años, si un día no tengo para vestir al chico voy a salir a robar (Marcos, relato de vida, 2017).

Otro eje de análisis que cabe considerarse vincula a los tipos de trabajos desarrollados y la relación que guardan con las trayectorias laborales de sus padres. Para algunos en experiencias desarrolladas en el campo, "Vendía los chanchos de mi papá, para ellos era la plata. El campo lo trabajaba mi papá, conmigo y mis hermanos [...] después trabajé en una fábrica y de albañil" (Mariano, relato de vida, 2017).Para otros se suman a estas tareas otras actividades: "Empecé a trabajar, lo primero fue albañilería porque mi 
papá tenía que revocar la casa, después en una chanchería, alambré campos y hasta en un taller" (Gerardo, relato de vida, 2017).

Por último, otra dimensión emergente es cómo se presenta el futuro laboral posterior al encierro. Se observa que en sus vidas se alterna el trabajo con actividades delictivas, el futuro aparece más como una expresión de deseo que posibilidad real:

[cuando salga] por ahí agarro trabajo y lo mismo voy y robo. Para tener más plata todavía. Capaz que cambie porque ahora soy mayor y no quiero estar muchos años en B [cárcel]. Capaz que empiece a trabajar, de albañil, no sé. Va a ser difícil cuando vuelva y me junte con mis amigos. (Marcos, relato de vida, 2017)

El futuro emerge así, como una fuerte disyunción entre "trabajar para subsistir" o "trabajar para la droga" como expresa uno de los jóvenes: "Vos salís trabajas de lunes a viernes y cuando es fin de semana puede pasar cualquier cosa. Yo pienso que cuando salga puedo trabajar, pero va a ser difícil cuando cobras porque lo gastas en drogas" (Kevin, relato de vida, 2017). Esta posibilidad se transforma en un conflicto difícil de dirimir a futuro, ya que viene enlazado a la oportunidad de delinquir.

Los jóvenes pueden reconocer que aunque prevalezcan actividades laborales precarias que refuerzan una lógica cortoplacista, con trabajos informales y transitorios, igual constituyen una alternativa de reconocimiento en la medida en que contribuyen al sostenimiento familiar (Milillo et al., 2016).

Por otro lado, las historias están signadas no sólo por la "heredabilidad" de las ramas de empleo entre padres e hijos, sino también por la transmisión generacional de que el trabajo es el terreno para el aprendizaje de las injusticias (Kessler, 2006). Por lo tanto, si las trayectorias laborales de estos jóvenes (y sus familias) están determinadas por la inestabilidad y precariedad, es difícil imaginar a futuro horizontes de mejores condiciones que viabilicen opciones de movilidad ascendente. 


\section{El papel del encierro en la transición a la adultez}

La institución en la que se encuentran alojados los jóvenes es un Centro de régimen cerrado que se corresponde con los dispositivos empleados para aplicar una medida de privación de libertad. Cuenta con barreras, alambrados, muros, puertas cerradas y personal de seguridad, a fin de cumplir con las medidas estipuladas. Su objetivo es "fomentar la capacidad de los adolescentes de ejercer derechos, respetar los derechos de los otros y asumir obligaciones en relación con una tarea (de aprendizaje, de capacitación, de convivencia) junto a un grupo de personas" (SENNAF \& UNICEF, 2015, p.12). Esto último aparece como un punto crítico en la narrativa de los jóvenes ya que al estar en la institución manifiestan una tensión entre vivenciar el encierro exclusivamente como un castigo y la posibilidad de resocialización.

En relación a la primera vivencia, los jóvenes mencionan que el tiempo presente es vivido como un tiempo sin sentido, en el que hacen un esfuerzo para "no pensar", como en este caso:

Es muy feo estar acá. Estás todo el día encerrado, tenés quilombo con los chicos, no es lindo acá. Cuando me pongo a pensar mucho en mi familia me empiezo a cortar. Para no pensar más me relajo y me acuesto a dormir. Me descargo. (Mariano, relato de vida, 2017)

Para otros, el encierro implica un sentirse preso, atrapado no sólo entre rejas sino como en pausa, esperando el momento de salir para comenzar una nueva vida.

Prefiero estar solo, ser un preso solo y aguantármelo solo. Estoy acumulando muchas cosas, pensar que no me voy a ir más. Hasta que me agarra la bronca un día y anda a saber qué puedo hacer. Tengo miedo de pegarle a alguien o de hacer quilombo. Me dicen algo y exploto, me saco. (Marcos, relato de vida, 2017) Ninguno de ellos tiene establecida una pena exacta, sino que viven con la expectativa de salir dentro de poco. Uno de los jóvenes expone esta espera como interminable: “Siempre que voy a Tribunales me dicen: 'un par de días más y te vas'. Fui cinco veces 
y siempre lo mismo, me estoy amohosando acá en cana" (Mariano, relato de vida, 2017).

Por otro lado, expresan que experimentan tensiones y conflictos en las relaciones cotidianas por tener que seguir reglas y códigos impuestos por sus pares. Así narran cómo fueron los primeros días en la institución:

No sabía cómo se vivía y andaba renegando porque me robaban la ropa o tenía que andar peleando, cada vez que me venían a robar tenía que pelear para que no me saquen la ropa, y así me fueron respetando. Me fui adaptando y aprendí a vivir adentro. (Kevin, relato de vida, 2017)

En la misma línea, este joven relata sobre los enfrentamientos que se suscitan entre sus pares, en donde evidencia cómo se reproducen las lógicas de dominación propias de la vida en la calle:

Cuando estábamos en el otro módulo siempre tenía que andar peleando. Empezaba a los puñetes y terminaba a los palazos, a los focazos; muchas veces terminas mal porque te abren, pegándote puñaladas. De los talleres sacan y hacen puntas y con eso te pegan. Siempre he peleado acá dentro, he ganado y he perdido. (Kevin, relato de vida, 2017)

En relación a la experiencia de imaginar rumbos diferentes hacia el futuro, es difícil pensar, el camino hacia la resocialización de estos jóvenes. Aunque pueden rescatar la presencia de referentes en el marco del encierro -que en cierto modo propician una subjetivación diferente- y actividades que promueven dicha resocialización (recreativas, escolares y aprendizaje de oficios), queda claro que todas estas acciones son insuficientes para revertir sus itinerarios delictivos. El joven reconoce:

Llega el director y nos habla, nos dice que se pueden hablar las cosas. Tenemos una buena relación, hace mucho que nos conocemos, charlamos. Los profesores son buenos, tomamos mates, compartimos criollos [pan], nos 
preguntan cómo estamos, salimos afuera a despejar la mente. (Kevin, relato de vida, 2017)

Asimismo, si bien la escolaridad que ofrece la institución forma parte del sistema formal de enseñanza, esta opción es desconocida o desestimada. Frecuentan dos horas por día la escuela y cuentan con un cuerpo docente que se encarga del desarrollo de las asignaturas. Así lo comentan: "Estudiamos literatura, matemática, ciudadanía, inglés, tecnología. Me gusta resolver cuentas, no escribir" (Lautaro, relato de vida, 2017).

Concurrir a la escuela se presenta como un requerimiento del Juez. Aveces esto está reñido con los deseos personales: "Estoy en $2^{\circ}$ año, rindiendo para pasar a tercero, me va bien. No me gusta, pero el Juez me pidió que la haga" (Kevin, relato de vida, 2017). Por otro lado, "el aprendizaje" y "el encierro" constituyen un binomio que no parecen vincularse, uno de los jóvenes expresa este dilema de un modo evidente:

Me gustaría terminar la escuela, pero en la calle. Acá no. Acá me hace doler la cabeza, se me pone la vista negra, me agarran mareos. Cuando vaya a mi casa y tenga la libertad voy a ir a la escuela.Acá piensan que es un socio-educativo. Pero acá ¿qué aprendes? (Mariano, relato de vida, 2017)

Aún en el caso de Marcos, para quien el recorrido escolar había tenía sentido, en este contexto no tiene igual valor: "No va a servir para nada esto porque no te van a dar una libreta. El día que me vaya no me van a dar nada para que siga cursando. Voy a empezar segundo año de vuelta afuera" (Marcos, relato de vida, 2017). En una primera lectura, y considerando los relatos de los jóvenes, nos preguntamos por la huella subjetiva que la condición de encierro deja en las posibilidades de simbolizar y el deseo de aprender. Pareciera que los procesos reflexivos y opciones personales se tornan muy difíciles bajo estas circunstancias.

La segregación y encarcelación del joven tiene como fin la supuesta "resocialización", pero lo cierto es que este modelo de coacción-castigo (que aísla, segrega e incapacita) resulta mucho más eficaz frente a la peligrosidad que supuestamente representan para 
la defensa social más que para su reconversión-redención (Daroqui, López, \& García, 2012). Se podría decir que estos jóvenes se ven expuestos a medidas que intentan proporcionarles vías para la construcción de un futuro diferente, aunque paradójicamente en contexto de encierro parecen acentuarse las condiciones de vulnerabilidad más que posibilitarse una auténtica transición a la vida adulta que no sea una repetición del mismo circuito: la pobreza- la vida en la calle- el consumo de sustancias- el delito- la institucionalización.

\section{Discusión}

A partir del análisis de los relatos biográficos de los jóvenes varones en conflicto con la ley se detectaron algunos eventos y circunstancias que dan cuenta del camino recorrido y sus modos de transitar la vida hacia la adultez. Si bien en su construcción fueron presentando puntos en común en las historias, que no apuntan a una generalización, nos aproximan a la singularidad de sus perspectivas de futuro.

Se observa que los relatos denuncian la conformación de recorridos delimitados por escenarios enmarcados por acontecimientos adversos signados por condiciones estructurales de vida y experiencias subjetivas que se entrelazan de tal modo que dificultan pensar la transición a la adultez. En consecuencia, tal como reflejan otros estudios (Mora Salas \& de Oliveira, 2014) las experiencias escolares y laborales son insuficientes para rebasar las desventajas que provienen de la urdimbre familiar, por lo que tienden a reproducir y acumular aún más las experiencias de fracaso que se vinculan con el universo del delito penal (Nebra, 2015).

En este marco, el trabajo nos sitúa ante los distintos modos en que los jóvenes trazan sus itinerarios de transición hacia la adultez que van: a) Desde "la continuidad del encierro" en el que se sienten atrapados en un circuito que les torna difícil su proyección y b) al trazado de un futuro incierto en el que se puede divisar una ruta marcada por el "deber ser" (acorde al sistema punitivo y de control) y otra por "el deseo personal" 
(finalización de la escolaridad y consecución de un trabajo para integrarse al sistema). Se advierte que estas dos últimas opciones responden a la reproducción de una lógica que avala la responsabilidad individual y descuida las dimensiones estructurales (Viscardi \& Barbero, 2010) en las que se inscriben las historias de estos jóvenes.

Finalmente, surge de este primer acercamiento un nuevo interrogante. Esto es en qué medida las acciones del Estado resultan efectivas para lograr la integración de los jóvenes a la sociedad. En esta aproximación, la intención fue recuperar las voces de los jóvenes que se encuentran privados de libertad, convirtiéndose la narrativa en un insumo valioso para el desarrollo de líneas de intervención (preventivas, educativas, asistenciales) orientadas a disminuir su vulnerabilidad. Por otro lado, si bien los resultados obtenidos podrían ser congruentes con la experiencia de otros estudios en contextos similares, una clara limitación es su abordaje metodológico de tipo exploratorio, que no permite su generalización, por lo cual sería deseable complementar el estudio no sólo con un mayor número de casos sino también atender a las diferencias de género y edades para enriquecer los resultados. Así mismo sería conveniente complementar el estudio con entrevistas a profesionales que apunten a dilucidar sus posicionamientos en relación al trabajo con los jóvenes, e incluir otros abordajes metodológicos que permitan evaluar los dispositivos destinados a ellos, con el fin de indagar en qué medida favorecen la creación de estrategias que posibiliten su re-afiliación, cortar círculos repetitivos, delimitar otros futuros posibles.

\section{Referencias}

Bobbio, A., Lorenzino, L., \& Arbach, K. (2016). Familia, barrio y sociedad: un estudio comparativo en jóvenes con y sin antecedentes delictivos de Argentina. Revista Criminalidad, $\quad 58(1), \quad$ 81-95. Recuperado de http://www.scielo.org.co/pdf/crim/v58n1/v58n1a06.pdf 
Crisafulli, L., \& León Barreto, I. (2015). Ritos y violencia en Córdoba. Los jóvenes y el Estado Penal). En M. Barrón \& G. Borioli (comp.), Jóvenes cordobeses: de los márgenes al empoderamiento: reflexiones sobre políticas (públicas) (pp. 201-212). Córdoba: SECyT, FFyH, UNC.

Daroqui, A., López, A., \& García, R. (Coord.) (2012). Sujeto de castigos: Hacia una sociología de la penalidad juvenil. Rosario: Homo Sapiens Ediciones.

Di Leo, P., \& Camarotti, A. (2017). Relatos biográficos y procesos de individuación juveniles en barrios marginalizados de Argentina. Revista Latinoamericana de Ciencias Sociales, Niñez y Juventud, 15(2), 1021-1034. doi:10.11600/1692715x.1521530082016.

Glaser, B., \& Strauss, A. (1967). The discovery of Grounded theory: Strategies for qualitative research. New York: Aldine Publishing.

Gonzales, N., \& Trillo, P. (2015). "Caer detenido": vulnerabilidades punitivas y trayectorias penalizadas. En P. Di Leo \& A. Camarotti (Coord.), Individuación y reconocimiento: experiencias de jóvenes en la sociedad actual (pp. 203-236). Buenos Aires: Teseo.

González-Laurino, C. (2015). La infracción adolescente a la ley penal en el centro del debate sobre seguridad pública en Uruguay. Revista Latinoamericana de Ciencias Sociales, Niñez y Juventud, 13(2), 951-962. doi:10.11600/1692715x.13228201014

Kessler, G. (2006). Sociología del delito amateur. Buenos Aires: Paidós.

Krauskopf, D. (2015). Los marcadores de juventud: la complejidad de las edades. Última década, 23(42),115-128. doi: 10.4067/S0718-22362015000100006

Leclerc-Olive, M. (2009).Temporalidades de la experiencia: las biografías y sus acontecimientos. Iberóforum. Revista de Ciencias Sociales de la Universidad Iberoamericana, $4(8)$, $1-39$.

Recuperado de 
http://www.idaes.edu.ar/pdf_papeles/TEMPORALIDADES\%20DE\%20LA\%20E XPERIENCIA\%20Michele\%20Leclerc-Olive.pdf

Ley N 10.903 Patronato de Menores. Boletín oficial de la República Argentina, Buenos Aires, Argentina, 27 de octubre de 1919. Recuperado de https://www.boletinoficial.gob.ar/\#!DetalleNormaBusquedaAvanzada/7010466/1 9191027

Ley N²2.278 Régimen Penal de la minoridad. Boletín Oficial de la República Argentina, Buenos Aires, Argentina, 28 de agosto de 1980. Recuperado de https://www.boletinoficial.gob.ar/\#!DetalleNormaBusquedaAvanzada/7082117/1 9800828

Ley $\mathrm{N}^{\circ} 26.061$ de Protección Integral de los Derechos de las Niñas, Niños y Adolescentes. Boletín Oficial de la República Argentina, Buenos Aires, Argentina, 26 de octubre de 2005. Recuperado de https://www.boletinoficial.gob.ar/\#!DetalleNormaBusquedaAvanzada/7280851/2 0051026

Milillo, N.A., Torillo, D. \& Farías. L (agosto, 2016). Trayectorias laborales de jóvenes que han estado privados de su libertad: hacia un análisis interpretativo. Trabajo presentado en el III Foro Latinoamericano de Trabajo Social, La Plata, Argentina. Recuperado de http://www.trabajosocial.unlp.edu.ar/uploads/docs/milillo_torillo_farias_gt_9.pdf Ministerio de Justicia y Derechos Humanos. Presidencia de la Nación (2019). Eje Penal. Equipo: Fortalecimiento de la Investigación Criminal. Sistema de Responsabilidad Penal Juvenil. Buenos Aires: Ministerio de Justicia y Derechos Humanos. Recuperado de https://www.justicia2020.gob.ar/eje-penal/sistema-penal-juvenil/

Ministerio de Trabajo, Empleo y Seguridad Social. Presidencia de la Nación. (2018) Provincia de Córdoba. Informe de diagnóstico laboral: Julio de 2018. Buenos 
Aires: Dirección General de Estudios Macroeconómicos y Estadísticas Laborales.

Recuperado

de http://www.trabajo.gob.ar/downloads/estadisticas/informesprovinciales/InfDiagL ab_2018JUL_Cordoba.pdf

Miranda, A., \& Corica, A. (2018). Gramáticas de la Juventud: reflexiones conceptuales a partir de estudios longitudinales en Argentina. En A. Corica, A. Freytes Frey, A. Miranda (Comps.), Entre la educación y el trabajo. La construcción cotidiana de las desigualdades juveniles en América Latina ( $\mathrm{pp} \mathrm{27-50).} \mathrm{Buenos} \mathrm{Aires:}$ CLACSO.

Mora Salas, M.\&de Oliveira, O. (2014). Los caminos de la vida: acumulación, reproducción o superación de las desventajas sociales en México. Revista Mexicana de Ciencias Políticas y Sociales, 59(220), 81-115. Recuperado de http://www.scielo.org.mx/pdf/rmcps/v59n220/v59n220a4.pdf

Nebra, M.J. (2015). “Los pibes chorros” Jóvenes en situación de vulnerabilidad penal y construcción de identidad(es): Políticas sociales y prácticas culturales de y para jóvenes en conflicto con la ley penal. HS- Horizontes Sociológicos- AAS-3(6), 106-118.

Roberti, E. (2017). Perspectivas sociológicas en el abordaje de las trayectorias: un análisis sobre los usos, significados y potencialidades de una aproximación controversial. Sociologías, 19(45), 300-335. doi: 10.1590/15174522-01900451

Salazar, M. (2018). Reforma penal juvenil y baja de edad de punibilidad. Los peligros del avance punitivo sobre niños, niñas y adolescentes. Equidad: Infancias $y$ adolescencias, 2, 1-5.

Sandoval Obando, E.(2014). Propensión a aprender de los Adolescentes Infractores de Ley: reflexiones desde el enfoque biográfico. Polis. Revista Latinoamericana, 13(37),251-273. doi: 10.4067/S0718-65682014000100015 
Secretaría Nacional de Niñez, Adolescencia y Familia (SENNAF), \& Fondo de las Naciones Unidas para la Infancia (UNICEF) (2015). Relevamiento Nacional sobre adolescentes en conflicto con la ley penal. Año 2015. Buenos Aires: UNICEF.

https://www.unicef.org/argentina/informes/relevamiento-nacional-sobre-adolesc entes-en-conflicto-con-la-ley-penal

Tenenbaum, G. (2016). Infracción y desistimiento: influencias familiares en los adolescentes en conflicto con la ley de la Ciudad de México. Revista Mexicana de Ciencias Políticas y Sociales. 61(227), 195-222. doi: $10.1016 / S 0185-1918(16) 30026-5$

Viscardi, N., \& Barbero, M. (2010). Políticas para menores infractores en Uruguay: tendencias sociales e institucionales en base al papel desempeñado por el Poder Judicial, La Policía y la prensa. O público e o privado, 15, 153-172.

Este artículo de investigación científica y tecnológica es parte del proyecto denominado "Procesos de subjetivación de los y las jóvenes en contextos de pobreza: Trayectorias y proyectos de vida." financiado por la Universidad de Católica de Córdoba e inscripto a la Secretaría de Investigación y Unidad Asociada al Conicet / Área en Ciencias Sociales y Humanidades / Facultad de Filosofía y Humanidades. Resolución Rectoral № 991/16.

\section{Declaración de contribución de los autores}

GC, PD, GA, contribuyeron al diseño e implementación de la investigación. Todos los autores participaron tanto del análisis de resultados como de la escritura del manuscrito, discutieron resultados y contribuyeron a su versión final. 
Formato de citación

Cardozo, G., Dubini, P. y Gonzalez, A. S. (2019). Transición de jóvenes varones en conflicto con la ley penal hacia la vida adulta en Córdoba (Argentina). Psicología, Conocimiento y Sociedad, 9(1), 31-58. doi: http://dx.doi.org/10.26864/PCS.v9.n1.6 